Research Article

\title{
Characterization of Local Nano-Heat Transfer Fluids for Solar Thermal Collection
}

\author{
Kawira Millien ii \\ Department of Physical Sciences, University of Embu, P.O. Box 6, Embu, Kenya \\ Correspondence should be addressed to Kawira Millien; kawira.millien@gmail.com
}

Received 22 April 2020; Accepted 7 July 2020; Published 7 August 2020

Academic Editor: Akbar Heidarzadeh

Copyright (c) 2020 Kawira Millien. This is an open access article distributed under the Creative Commons Attribution License, which permits unrestricted use, distribution, and reproduction in any medium, provided the original work is properly cited.

Performance of organic oils in solar thermal collection is limited due to their low thermal conductivity when they are compared to molten salt solutions. Extraction of organic oils from plants can be locally achieved. The purpose of this study was to investigate the effect of use of copper nanoparticles in some base local heat transfer fluids (HTFs). Addition of volume fraction of $1.2 \%$ of the copper nanoparticles to oil-based heat transfer fluids improved their thermal conductivity as deduced from the thermal heat they conducted from solar radiation. The oil-based copper nanofluids were obtained by preparation of a colloidal solution of the nanoparticles. Impurities were added to increase the boiling point of the nano-heat transfer fluids. Stabilizers were used to keep the particles suspended in the oil-based fluids. The power output of the oil-based copper nano-heat transfer fluids was in the range of $475.4 \mathrm{~W}$ to $1130 \mathrm{~W}$. The heat capacity of the steam in the heat exchanger was $93.7 \%$ dry and had a thermal capacity of $5.71 \times 10^{3} \mathrm{~kJ}$. The heat rate of flow of the oil-based copper nano-heat transfer fluids was an average of $72.7 \mathrm{Js}^{-1} \cdot \mathrm{kg}^{-1}$ to $89.1 \mathrm{Js}^{-1} \cdot \mathrm{kg}^{-1}$. The thermal efficiency for the oil-based copper nano-heat transfer fluids ranged from 0.85 to 0.91 . The average solar thermal solar intensity was in the range $700 \mathrm{Wm}^{-2}$ to $1180 \mathrm{Wm}^{-2}$. The heat exchanger used in this study was operating at $4.15 \times 10^{3} \mathrm{~kJ}$ and a temperature of $500.0^{\circ} \mathrm{C}$. The heat transfer fluids entered the exchanger at an average temperature of $381^{\circ} \mathrm{C}$ and exited at $96.3^{\circ} \mathrm{C}$ and their heat coefficient ranged between $290.1 \mathrm{Wm}^{-2 \circ} \mathrm{C}$ and $254.1 \mathrm{Wm}^{-2 \circ} \mathrm{C}$. The average temperatures of operation ranged between $394.1^{\circ} \mathrm{C}$ and $219.7^{\circ} \mathrm{C}$ with respective temperature efficiencies ranging between $93.4 \%$ and $64.4 \%$. It was established that utilization of copper nanoparticles to enhance heat transfer in oil-based local heat transfer fluids can mitigate energy demand for meeting the world's increasing energy uses, especially for areas inaccessible due to poor land terrain.

\section{Introduction}

Solar thermal collectors are used for solar thermal collection and some of their various applications include heating and cooling of houses, drying agriculture food materials, and water desalination processes. The heat collected by the oilbased nanofluids passing through the absorber was exchanged between the oil-based nano-HTFs and a secondary fluid in the heat exchanger. It was noted that when Darcy number and porosity diminishes, the crash between the fluid flow and the pores of the permeable screen increased [1], and in this manner the passing fluids gave more space to contact with the permeable media which have inward heat generation for heat transfer. Table 1 shows the acronyms, abbreviations, and subscripts used in this study.
The particles enhance certain properties of the fluid such as thermal conductivity and further study can reveal the nature of the observed enhanced conductivity. In this study, the copper nanoparticles in oil base gave a large volume-tosurface-area ratio for thermal transfer. The copper nanoparticles were prepared using chemical reduction procedure [2]. The particles of copper of size $28.55 \mathrm{~nm}$ were obtained. It was established that nanoparticles can be prepared in onestep process such as in the case of one-step synthesis system of preparing carbon/water nanofluid by use of plasma arch welding equipment [3]. Carbon nanotube nanoparticles can achieve thermal conductivity of $3000 \mathrm{~W} / \mathrm{mK}$ and 2000 aspect ratio. Suspended nanoparticles enhanced the intended thermal conduction which led to superior performance due to their low momentum and improved mobility. The heat 
TABle 1: Acronyms, abbreviations, and subscripts.

\begin{tabular}{|c|c|}
\hline \multicolumn{2}{|l|}{ Nomenclature } \\
\hline$\eta_{v}$ & Viscosity $\left(\mathrm{Nm}^{-2} \mathrm{~s}^{-1}\right)$ \\
\hline$q_{m}$ & Volume flow rate $\left(\mathrm{m}^{3} \mathrm{~s}^{-1}\right)$ \\
\hline$\eta_{T}$ & Temperature efficiency (\%) \\
\hline$\eta_{e}$ & Energy efficiency (\%) \\
\hline$\eta_{\mathrm{HTF}}$ & Efficiency of nanofluid (\%) \\
\hline$Q_{\text {use }}$ & Useful heat $(\mathrm{J})$ \\
\hline$P_{\text {Inc }}$ & Solar power intensity $\left(\mathrm{Wm}^{-2}\right)$ \\
\hline$W_{\min }$ & Minimum capacity heat rate \\
\hline$W_{\max }$ & Maximum capacity heat rate \\
\hline $\operatorname{Pr}$ & Prandtl number \\
\hline$\dot{q}$ & Heat flux \\
\hline$c_{p, m}$ & Specific capacity at constant mass \\
\hline UA & Overall conductance $\left(\mathrm{W} / \mathrm{m}^{2 \circ} \mathrm{C}\right)$ \\
\hline $\mathrm{U}$ & Overall coefficient of heat transfer $\left(\mathrm{W} /{ }^{\circ} \mathrm{C}\right)$ \\
\hline \multicolumn{2}{|l|}{ Abbreviations } \\
\hline HTF & Heat transfer fluid \\
\hline NTU & Number of heat transfer units \\
\hline A & Total transfer of heat surface area \\
\hline$\omega$ & Dimensionless heat capacity ratio \\
\hline$A$ & Area \\
\hline$T$ & Temperature \\
\hline$l$ & Length \\
\hline$\varepsilon$ & Effectiveness \\
\hline \multicolumn{2}{|l|}{ Subscripts } \\
\hline ht & Hot \\
\hline$o, c$ & Outlet cold stream \\
\hline$i, h$ & Inlet hot stream \\
\hline$i, c$ & Inlet cold stream \\
\hline$p, m$ & Pressure, mass \\
\hline $2, i$ & Stream 2 , inlet \\
\hline $2, o$ & Stream 2 , outlet \\
\hline $\overrightarrow{1}, i$ & Stream 1 , inlet \\
\hline $\mathrm{cm}$ & Value with constant property \\
\hline$r$ & Direction \\
\hline
\end{tabular}

transfer mechanism in nanoparticle fluid-based substances takes place by micro convention mechanism. The stabilizing agents were used to ensure that the nanoparticles did not sediment; hence, the system did not clog. For instance, multi-walled carbon nanotubes suspended in engine oil increase conductivity 20,000 times [4]. It was observed that increasing the buoyancy ratio resulted in an increase in the local Nusselt number augments while the increase of Lewis number had an opposite influence on the Nusselt number as the convective heat transfer rate index [5].

A nanoparticle suspension can also be made in a twostep process involving synthesis of the particle powder and the dispersal of the particles in a fluid base [6]. This process is mostly used for industrial application. In Kenya, there are various types of seeds such as castor oil seeds, sunflower, coconuts, etc., whose oil is locally extracted. In this study, some local heat transfer oils were used as base for copper nanoparticles for the purpose of enhancing their thermal conductivity. Investigation of the use of the extracted oils with copper nanoparticles suspension for solar heat transfer was conducted. Oil-based copper nano-heat transfer fluids conveyed the heat from thermal collectors to a secondary fluid, in the heat exchanger, which vaporized to steam and drove a turbine. The availability of oil base for copper nanoparticles makes the nano-heat transfer fluids more affordable for power generation. Oils can be extracted affordably from raw material sources such as seeds using local technology. Heat transfer fluids used in parabolic trough collectors can reach temperatures of $400^{\circ} \mathrm{C}$ making the technology the most mature for solar thermal power generation [7]. In Mojave Desert, thermal oil flowing through a solar collector reaches temperatures of $393^{\circ} \mathrm{C}$, and water conducts thermal heat from the oil and turns to steam that drives turbines for electrical power generation [8]. Improvement in performance of oil-based copper nano-thermal transfer fluid plays a crucial role in enhancing the efficiency and producing thermal systems of higher performances [9]. Characterization of nanoparticles can be done by FESEM and XRD tests. The mass fraction range of fluids with nanoparticles and thermal conductivity in various temperature ranges conforms to standards such as the ASTM D2717-95.

Adding of copper particles to heat transfer fluids improved their efficiency of heat conduction [10]. Studies show that oil-based copper nano-heat transfer fluids can achieve efficiencies of $97.45 \%$ at $30^{\circ} \mathrm{C}$ and $48.92 \%$ at $80^{\circ} \mathrm{C}$ at nanoparticle concentrations of 0.02 [11]. Solar power technologies investment costs continue to reduce and in some instances the cost is competitive compared to fossil fuel costs [12]. Further research on third-generation heat transfer fluids is aimed at producing heat transfer temperatures in the operation range of $800^{\circ} \mathrm{C}$ [13]. Thermal conductivity measurements are done against a range of temperatures and the concentration. It was observed that nanoparticle concentration was enhanced with the number of particles per cubic centimeter of the heat transfer fluid and temperature [4].

In a study of heat transfer fluids, Syltherm 800 was observed to undergo thermal losses due to low heat capacity [9]. Transmission Electron Microscope is used to study the particle size and the structure. In the hand book by Franz and Kai [14], high aspect ratios of $10: 1$ to $20: 1$ were obtained. In related work, Sivashanmugam [15], nanoparticles obtained high aspect ratios of the nanoparticles produced.

\section{Materials and Methods}

2.1. Preparation of Oil-Based Copper Nano-Heat Transfer Fluid. The method used for producing the copper nanoparticles was the continuous flow microfluidic microreactor for synthesis of copper particles [6]. The prevention of the copper nanoparticles from aggregation was done by producing lipophilic copper particles [16] where the copper nanoparticles were prepared and modified by O,O-di-ncetyldithiophosphoric acid. The volume fraction used for making the colloidal fluid was $1.2 \%$. The surface modification was achieved by the organic ligands which prevented clustering of the nanoparticles. A volume of $1.0 \times 10^{-4} \mathrm{~m}^{3}$ of methylbenzene was added to $2.0 \times 10^{-1} \mathrm{~m}^{3}$ of the respective oils before preparation of the copper nanoparticles colloidal fluids. 
2.2. Solar Thermal Collection. A volume of $2.0 \times 10^{-1} \mathrm{~m}^{3}$ of the oil-based copper nano-heat transfer fluids was passed through the parabolic trough solar collector of area of $32 \mathrm{~m}^{2}$ which was connected to a heat exchanger [17]. The transfer of solar thermal heat to form steam took place in the heat exchanger [18]. The steam expanded in the turbine and propelled the blades. The steam turbine was coupled to a $1500 \mathrm{~W}$ generator that converted the mechanical energy into electrical power. The hot oil-based copper nano-heat transfer fluids flowed through coiled copper tubes in the heat exchanger. The water on the pressurized shell side conducted the solar thermal heat from the hot oil-based copper nano-heat transfer fluids and turned into steam. The solar power intensity was measured using the solar power intensity meter. During the solar thermal collection, the solar power intensities ranged between $700 \mathrm{Wm}^{-2}$ and $1180 \mathrm{Wm}^{-2}$.

2.3. Measurement of Mass Flow Rate. Mass flow rate was measured by use of Transit Time Flow Meter at intervals of five minutes. The mass flow rate of heat exchanger was measured using digital flow meters and rheometers. The volume control valve was adjusted to allow maximum volume of $15 \mathrm{kgh}^{-1}$ of water to be discharged during high demand and a minimum amount to flow of $5 \mathrm{kgh}^{-1}$ of steam during off-peak demand.

The pressurized steam on the shell side of the heat exchanger was caused by the hot nano-heat transfer fluids. The viscosity was measured using a viscometer which was located at the entrance and exit of solar collector and the exchanger.

Viscosity, $\eta_{v}$, of fluids was obtained by use of

$$
\eta_{v}=\frac{\pi \Delta \operatorname{Pr}^{4}}{8 q_{m} l}
$$

where $q_{m}$ is the volume rate flow and $l$ represents length of the tube while Pr represents the Prandtl number.

2.4. Measurement of Efficiency. The total amount of heat absorbed by the oil-based copper nano-heat transfer fluids was determined from mass flow rate at ambient temperature flow, temperature change, and specific heat capacities of the oil-based copper nano-heat transfer fluids. The measurement flow rate and temperature drop were measured using digital oil flow meters and thermocouples, respectively, located at the entry and exit of fluid to and from the heat exchanger.

Equations (1) and (2) were used to determine efficiency of oil-based copper nano-heat transfer fluids.

The mean temperature efficiency of oil-based copper nano-heat transfer fluids was determined by use of

$$
\eta_{T}=\frac{T_{2, i}-T_{2, O}}{T_{2, i}-T_{1, i}} \times 100 .
$$

To determine the energy efficiency, $\eta_{e}$, the following equation was used:

$$
\eta_{e}=\frac{\text { energy exchanged }}{\text { total energy supplied }} \times 100 .
$$

The efficiency of conversion of solar power by the receiver in which the oil-based copper nano-heat transfer fluids flowed was determined by use of the following equation [19]

$$
\eta_{\mathrm{HTF}}=\frac{Q_{\text {useful }}}{P_{\mathrm{Inc}}},
$$

where $Q_{\text {useful }}$ is heat output rate from the oil-based copper nano-heat transfer fluids and $P_{\text {Inc }}$ is the solar power intensity.

Addition of copper nanoparticles increased the efficiency of nanofluids by $10 \%$ compared to when the base fluid did not have the nanoparticles [20].

2.5. Heat Transfer Units. The size of heat exchanger corresponded to the number of transfer of heat units. The number of transfer of heat units was obtained using the following equation [21].

$$
\mathrm{NTU}=\frac{\mathrm{UA}}{W_{\min }},
$$

where $W_{\min }$ refers to smaller capacity heat rate, UA refers to overall conductance, A refers to total area of heat transfer $\left(\mathrm{m}^{2}\right)$, and $\mathrm{U}$ refers to overall coefficient of heat transfer (W/ $\mathrm{m}^{20} \mathrm{C}$ ). The overall conductance was determined from the product of overall heat coefficients for the different nanofluids and the heat transfer area.

Fluid heat capacity ratio, $\omega$, was obtained by use of the following equation [22]

$$
\omega=\frac{W_{\min }}{W_{\max }},
$$

where $W_{\min }$ represents lower capacity of heat of duo streams or lower heat capacity rate and $W_{\max }$ higher heat capacity. In the inner copper tube of the heat exchanger, hot nano-heat transfer fluids' temperature was reduced by the stream of water flowing in the shell of exchanger and the overall nanofluid coefficient during operation was determined by use of

$$
U=\frac{W_{\min }}{A} \cdot \mathrm{NTU} .
$$

The magnitudes of $U$ accounted for all other factors that affected the thermal performance.

The overall heat transfer conductance, UA, was obtained by use of equation (6). Thermal conductivity of copper tube in the heat exchanger was $26 \mathrm{Wm}^{-1} \cdot \mathrm{K}^{-1}$ [23]. The magnitude of effectiveness of exchanger was obtained from the magnitude of thermal heat conducted from the nanofluids, by the water which flowed on the pressurized side of exchanger and was normalized with the maximum possible enthalpy change considering no heat losses.

The effectiveness, $\varepsilon$, of the heat exchanger was obtained by use of 


$$
\varepsilon=\frac{\text { Actual heat transfer }}{\text { Maximum possible heat transfer }} .
$$

The steam formed exited from the shell side of exchanger through the side outlet of the turbine. Heat transfer coefficients for the oil-based copper nano-heat transfer fluids were determined using documented details [24]. Area of baffles was $0.00038 \mathrm{~m}^{2}$, tube spacing was $0.04 \mathrm{~m}$, and the oilbased copper nano-heat transfer fluid average velocity was $8.0 \mathrm{~ms}^{-1}$. Temperature efficiencies of the heat exchanger streams were also an important measure of performance of the exchanger. The oil-based nanofluids' efficiency based on temperature was determined using the following equation [25].

$$
\eta_{\mathrm{ht}}=\frac{T_{i, h}-T_{o, h}}{T_{i, h}-T_{i, c}} \times 100,
$$

where $\eta_{\mathrm{ht}}$ is the hot fluid efficiency, $T_{o, c}$ is outlet fluid's temperature at ambient temperature stream, $T_{i, h}$ is inlet hot stream temperature, $T_{i h}$ is temperature of the inlet for hot stream, and $T_{i, c}$ is inlet fluid temperature at ambient temperature stream.

The temperature efficiency of the water at ambient temperature was determined using the following equation [26];

$$
\eta_{T}=\frac{T_{o, c}-T_{i, c}}{T_{i, h}-T_{i, c}} \times 100,
$$

where $T_{o, c}$ is temperature of outlet of water at ambient temperature stream, $T_{i, c}$ is water inlet temperature at ambient temperature stream, $T_{o, h}$ is temperature of outlet for hot stream and $T_{i, h}$ is temperature of inlet for hot stream.

Rate fluid hot fluid flux, $\dot{q}$, at the entrance and exit of heat exchanger was obtained using

$$
\dot{q}=q c_{p, m} \Delta T,
$$

where $\dot{q}$ refers to heat flow rate, $q$ refers to heat magnitude, $c_{p, m}$ refers to specific capacity at constant mass, and $\Delta T$ is the temperature change.

\section{Results and Discussion}

3.1. Performance of Oil-Based Copper Nano-Heat Transfer Fluids. The oil-based copper nanofluids conducted solar thermal heat energy which was in turn conducted away by the water flowing through the pressurized side of the shell of exchanger. Copper nanoparticles impurities which were added increased boiling point of the fluids to between $363.2^{\circ} \mathrm{C}$ of nano-castor oil heat transfer fluid and $447.5^{\circ} \mathrm{C}$ for the unused copper nano-heat transfer fluid. The viscosity of the oil-based copper nanofluids is as shown in Figure 1. This was at a temperature of $351^{\circ} \mathrm{C}$, solar power intensity of $832 \mathrm{Wm}^{-2}$, and a pressure of $4.2 \times 10^{5} \mathrm{~Pa}$. The viscosity decreased with the increase in the solar power intensity. The fluids were kept under pressure to increase the flash points. The heat transfer number of exchanger was obtained as 1.20. Avocado oil-based copper nanofluid had the least viscosity and conducted more heat compared to the other nanofluids

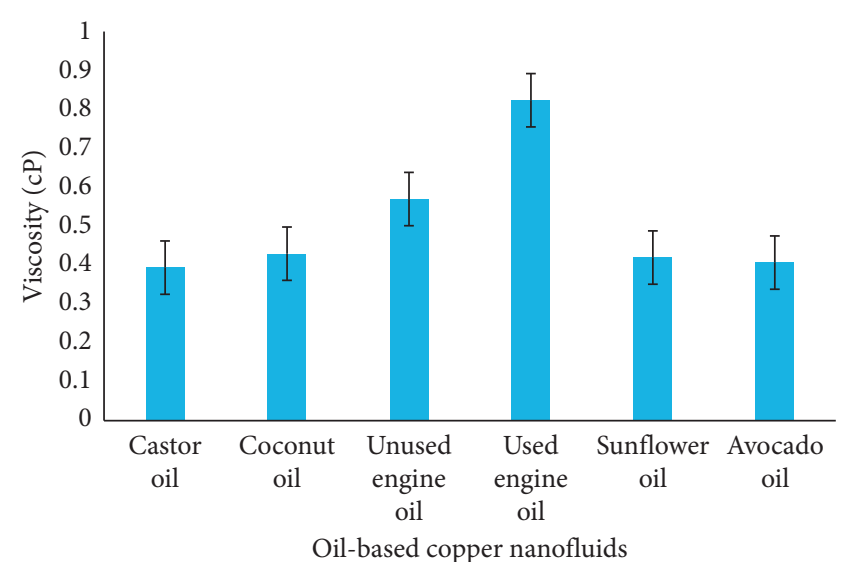

Figure 1: Viscosity of oil-based copper nano-heat transfer fluids.

since it took more time to move over the $5 \mathrm{~m}$ length of the solar collector. The change in viscosity of the oil-based nanofluids was $0.01 \%$ when compared to the viscosity of the respective engine oil heat transfer fluids.

Figure 2 shows the efficiency with which the oil-based copper nano-heat transfer fluids transmitted the solar thermal heat they conducted to water for steam formation. The unused engine oil-based nanofluid achieved the highest efficiency of 0.827 compared to castor-oil-based nanofluid which achieved the lowest efficiency of 0.612 . The castor oil degraded more with increase in temperature compared to the engine oil. The unused copper nanofluid had the highest efficiency of conducting solar thermal heat which was conducted by water to form steam in the heat exchanger.

Figure 3 shows the power output of the oil-based copper nano-heat transfer fluids at a power intensity of $1100 \mathrm{Wm}^{-2}$ and at a pressure of $1.6 \times 10^{5} \mathrm{Nm}^{-2}$. The unused engine oilbased copper nanofluid produced the highest amount of power. The castor oil copper nanofluid produced the lowest power because it became degraded faster compared to other nanofluids in this study. There was presence of black carbon particles in the oil-based copper nano-heat transfer fluids. In terms of intensity, unused engine oil had the least black carbon color intensity and the castor oil had the highest intensity of the black color intensity at operation temperatures above $150^{\circ} \mathrm{C}$. Stability of copper nano-heat transfer fluids deteriorated faster and more intensely beyond $389.6^{\circ} \mathrm{C}$. The power output produced by the respective heat transfer fluids is as shown in Figure 3. Beyond the said temperature, the power output reduced to less than $50 \mathrm{~W}$ for the unused oil-based nanofluid to less than $20 \mathrm{~W}$ for the castor-oil-based heat transfer fluid.

The solar power intensity was in the range $938.4 \mathrm{Wm}^{-2}$ to $1100.4 \mathrm{Wm}^{-2}$. The water which flowed on the pressurized side of shell of exchanger conducted more heat as the pressure was increased and it turned into steam. Engine oilbased nano-copper fluids conducted more thermal heat compared to the plant-based copper nanofluids used in this study. This was because the engine oils were synthetic in nature and degraded at higher temperatures of operation. The unused engine showed presence of carbon particles at a temperature of $410^{\circ} \mathrm{C}$. Oil-based copper nano-heat transfer 


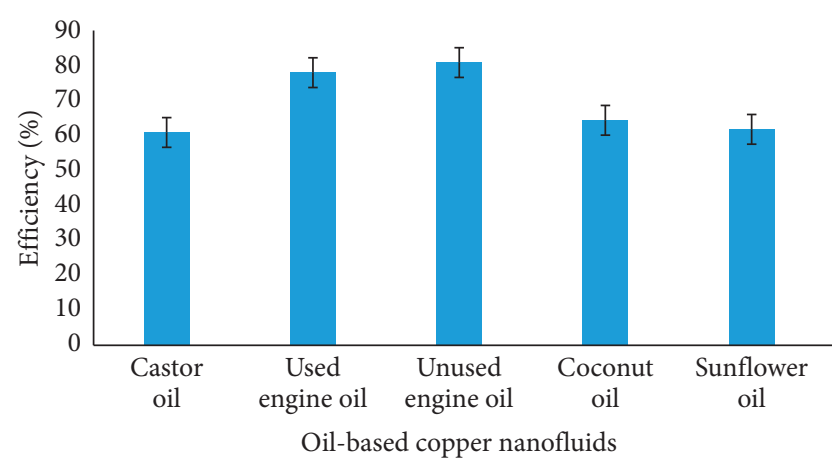

Figure 2: Efficiency of the oil-based copper nano-heat transfer fluids.

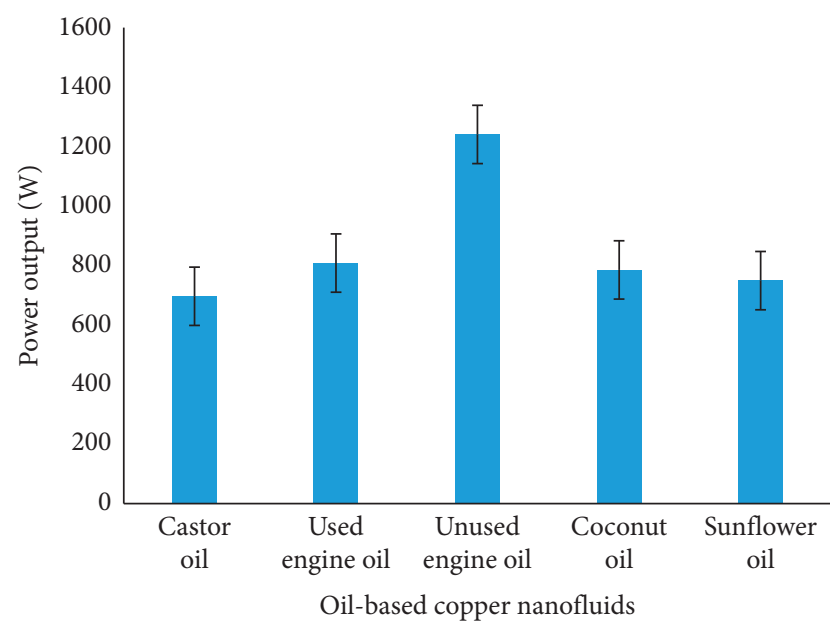

FIGURE 3: Maximum power output for oil-based copper nano-heat transfer fluids.

fluids under pressure in collector conducted a higher amount of solar thermal heat as compared to when no pressurization of the collector was done. In this study, the heat transfer was enhanced by addition of nanoparticles to the base fluids while in other studies the heat transfer was enhanced by use of fins of different types with considerations of variable thermal physical and geometric parameters [27]. The studies intend to lay a basis for geometrical modifications of extended surfaces based on the cost and availability of space for optimum heat transfer.

The heat conducted by the copper nanofluids was larger with respect to solar power intensity falling on the collector area as shown in Figure 4. The amount of heat collected was due to the increased boiling points and the presence of the copper nano-suspended particles in the solar thermal heat conducting nanofluids. The heat conducted by nanofluids had the effect of the thermal conductivity of the nanofluids increasing threefold in the study conditions given. Turbulence within the nanosuspension and through the copper metallic receiver to the surroundings accounted for energy losses. Although the receiver was coated with a thin film of solar absorptance of 0.95 , some losses were experienced at higher temperatures of operation which were between $150^{\circ} \mathrm{C}$ and $400^{\circ} \mathrm{C}$.

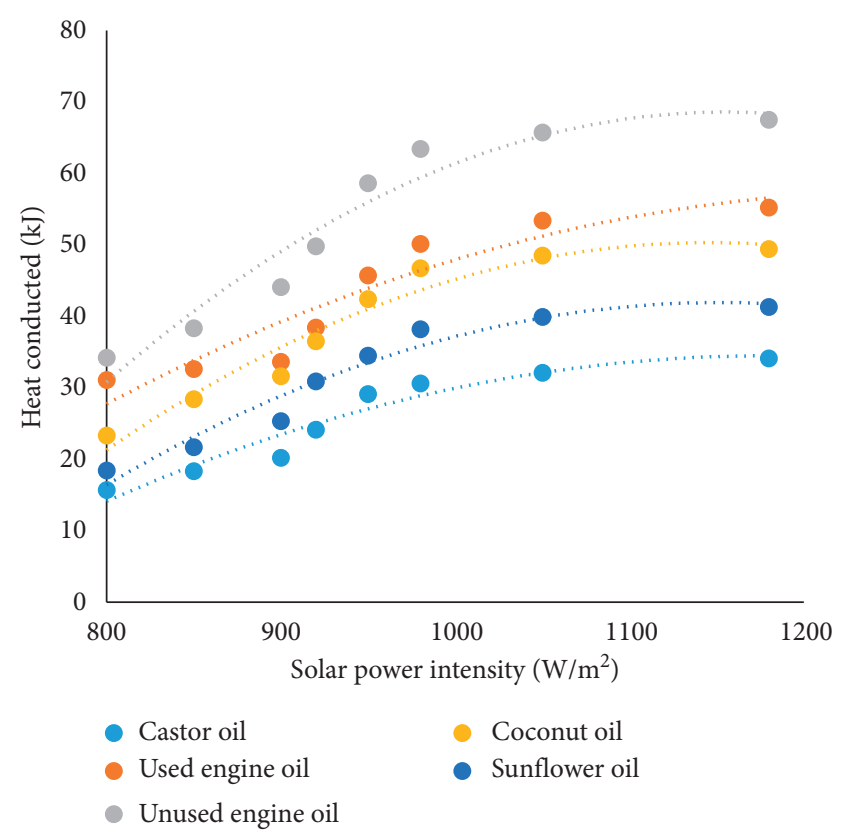

Figure 4: Average heat conducted against average solar power intensities.

The effectiveness of each of the streams was an average of 0.87 for the oil-based copper nano-heat transfer fluids flow (tube side) and an average of 0.94 for the hot water under pressure.

The percentage heat losses for the hot oil-based copper nano-heat transfer fluids occurred at an average temperature of $273.8^{\circ} \mathrm{C}$ and at an average pressure of $1.2 \times 10^{5} \mathrm{Nm}^{-2}$. The percentage losses are as shown in Table 2. Higher temperatures of the copper nano-based fluids caused an increase in percentage losses of the fluids as shown in Table 2.

Table 3 shows the temperature efficiencies of the oilbased copper nano-heat transfer fluids at an average temperature of $153.9^{\circ} \mathrm{C}$, pressure of $6.1 \times 10^{5} \mathrm{Nm}^{-2}$, and a solar power intensity of an average of $1067.4 \mathrm{Wm}^{-2}$. The efficiencies increased with magnitude of the heat conducted by the oil-based copper nano-heat transfer fluids. The temperature efficiencies of the oil-based copper nano-heat transfer fluids increased with increase in solar power intensity. The unused oil-based nanofluid achieved the highest temperature of $93.4 \%$ at a temperature of operation of $394.1^{\circ} \mathrm{C}$ whereas the castor-oil-based heat transfer fluid achieved temperature efficiency of $64.4 \%$ at a temperature of operation of $219^{\circ} \mathrm{C}$.

The temperature efficiency of the oil-based copper nanoheat transfer fluids increased with the temperatures of operation. Increase in solar power intensity led to increase in the operational temperatures of the oil-based copper nanoheat transfer fluids. Temperature efficiencies were an indicator of performance of the oil-based copper nano-heat transfer and hence unused engine oil-based nanofluid performed the best while the castor-oil-based nanofluid performed the worst out of the five studied copper particles oil-based nanofluids. The heat coefficient for the oil-based copper nano-heat transfer fluids and their corresponding 
TABLE 2: Percentage heat losses for the oil-based copper nano-heat transfer fluids.

\begin{tabular}{lcc}
\hline Fluid & Heat (KJ) & Percentage loss (\%) \\
\hline Castor oil & 16697.3 & 5.85 \\
Sunflower oil & 16498.5 & 5.6 \\
Coconut oil & 16991.3 & 5.95 \\
Used engine oil & 172744.7 & 6.1 \\
Unused engine oil & 17769.6 & 6.4 \\
\hline
\end{tabular}

TABLE 3: Temperature efficiencies of nanofluids at average operational temperatures.

\begin{tabular}{lcc}
\hline Oil-based copper nano-heat transfer fluids fluid & Average temperature of operation $\left({ }^{\circ} \mathrm{C}\right)$ & Temperature efficiency $(\%)$ \\
\hline Unused engine oil & 394.1 & 93.4 \\
Used engine oil & 365.6 & 83.9 \\
Coconut oil & 297.9 & 79.6 \\
Sunflower oil & 275.4 & 70.6 \\
Castor oil & 219.7 & 64.4 \\
\hline
\end{tabular}

TABLE 4: Average variation of heat coefficient with steam flow rate.

\begin{tabular}{lcc}
\hline Fluid & Heat coefficient $\left(\mathrm{W} / \mathrm{m}^{2 \circ} \mathrm{C}\right)($ average) & ${\text { Steam flow rate }\left(\mathrm{kgs}^{-1}\right)\left(\mathrm{average}^{-}\right.}$ \\
\hline Unused engine oil & 290.1 & 7.49 \\
Used engine oil & 284.4 & 6.53 \\
Coconut oil & 279.6 & 5.61 \\
Sunflower oil & 267.1 & 4.67 \\
Castor oil & 254.5 & 3.69 \\
\hline
\end{tabular}

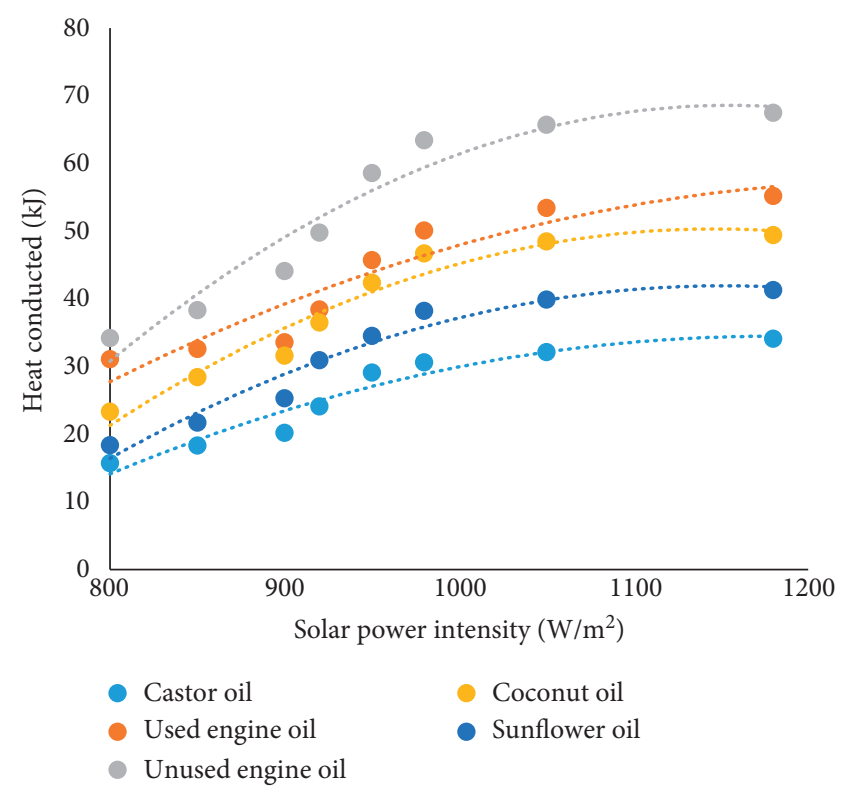

Figure 5: Heat conducted by nanofluids against solar power intensity.

steam flow rates are as shown in Table 4. However, $\mathrm{Al}_{2} \mathrm{O}_{3}$ nanofluid showed highest enhancement in heat transfer coefficient because of higher specific heat as compared to other studied nanofluids [28]. The flow of steam from turbine increased with respect to thermal heat coefficient in addition to higher temperatures of operation and the stability of the oil-based nano-heat transfer fluid.

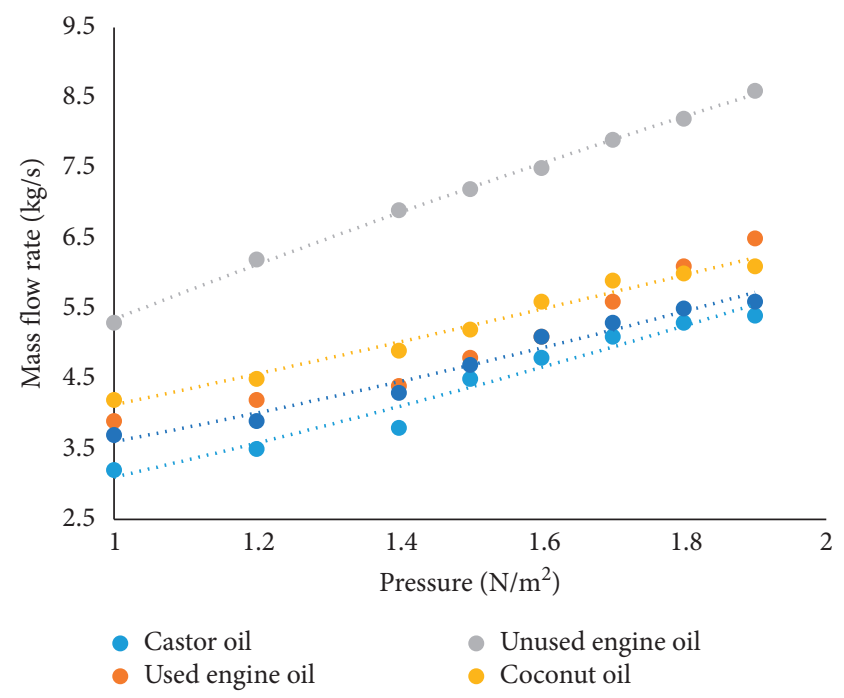

FIGURE 6: Mass flow rate of steam against pressures of operation.

The heat loss coefficient increased with amount of heat conducted by the oil-based copper nano-heat transfer fluids. The solar power intensity was an average solar power intensity of $953.7 \mathrm{Wm}^{-2}$. The heat coefficient was proportional to the solar power intensity. The steam flow rate increased with the heat coefficient of the oil-based copper nanofluids. During the cloudy and diffuse solar radiation periods, there was reduced mass flow rate of the steam and hence lower heat coefficients for the oil-based nano-heat transfer fluids. 
Figure 5 shows that increase in solar power intensity led to increased amount of heat conducted by the copper nanofluids. The heat conducted was three times the amount conducted when the fluids have no nanoparticles.

Figure 6 shows that steam flow rate of exchanger increased with respect to rising magnitudes of pressures of operation. Pressure increased the boiling point of the water. The steam from the exchanger entered the exchanger at an average temperature of $381.3^{\circ} \mathrm{C}$ and exited at an average of $96.3^{\circ} \mathrm{C}$ and it was fed back to the collector. The nano-heat transfer fluids required to be replaced after three days due to the effect of degradation which increased with increasing operation temperatures.

\section{Conclusion}

Solar thermal collection by use of local copper nanofluids can be used to provide power for off-grid areas with solar power intensities of between $900 \mathrm{Wm}^{-2}$ and $1100 \mathrm{Wm}^{-2}$. The $1.2 \%$ concertation of the copper nanoparticles increased the thermal conductivity significantly as was seen from the amounts of heat conducted by the oil-based nano-heat transfer fluids. The power produced was an average of $1130 \mathrm{~W}$. The steam flow rates realized in this study were between $7.49 \mathrm{~kg} / \mathrm{s}$ and $3.69 \mathrm{~kg} / \mathrm{s}$ that can be scaled up and be utilized in process heat industries, where agricultural food processing, mining, power generation, etc. are in high demand. The colloidal suspensions of local oil-based copper nanofluids conducted solar thermal heat from solar thermal radiation in the range of $20 \mathrm{Kj} / \mathrm{s}$ to $80 \mathrm{Kj} / \mathrm{s}$ during clear sky conditions. The performance of the oil-based fluids was enhanced threefold by use of copper nanoparticles. The impurities were used to increase the boiling points of the nanofluids. Stabilizing the heat transfer fluids at temperatures beyond $380^{\circ} \mathrm{C}$ was a challenge due to degradation of the oil-based fluids. Industrialization of third-world countries without environmental pollution requires enhancement of nano-heat transfer fluids that operate at higher temperatures with minimal degradation. Significant long-term oil-based nanofluid settlement and the decreased rates of flow require effective surfactants to minimize blockage of system passages. The use of effective nanofluid stabilizers is recommended without compromising the thermal conductivity of the HTF. The atomic level interactions between the base fluid and the nanoparticles which leads to enhanced thermal conductivity of the oil-based heat transfer fluids require further investigation.

\section{Data Availability}

Data are available from the author upon request.

\section{Conflicts of Interest}

The author declares no conflicts of interest.

\section{Acknowledgments}

University of Embu is appreciated for providing the laboratory space, equipment, and apparatus for the study.

\section{References}

[1] M. Alkasassbeh, Z. Omar, F. Mebarek-Oudina, J. Raza, and A. Chamkha, "Heat transfer study of convective fin with temperature-dependent internal heat generation by hybrid block method," Heat Transfer-Asian Research, vol. 48, no. 4, pp. 1225-1244, 2019.

[2] K. Ayesha, R. Audi, Y. Raffia, and C. Ren, "A chemical reduction approach to the synthensis of copper naonoparticles," International Nano Letters, vol. 6, pp. 21-26, 2015.

[3] T. Tun-Ping, C. Ching-Min, and P. Feng-Yi, "Preparation and characterization of carbon nano fluids by a plasma arch nanoparticle synthesis system," Nanoscale Research Letters, vol. 6, no. 1, p. 293, 2011.

[4] R. Afifa, K. Saleh, B. Moncef et al., "Study of thermal conductivity of synthesized $\mathrm{Al}_{2} \mathrm{O}_{2}$ - water nanofluid by pulsed laser ablation in liquid," Journal of Molecular Liquids, vol. 304, Article ID 112694, 2020.

[5] K. Alibakhsh, D. Reza, M. Omid et al., "Nano fluid flow and heat transfer in porous media; a review of the latest developments," Journal of Heat and Mass Transfer, vol. 101, pp. 778-791, 2017.

[6] X. Wei and L. Wang, "Synthesis and thermal conductivity of microfluidic copper nano fluids," Particuology, vol. 8, no. 3, 2010.

[7] J. Jalili, S. Gorjian, and M. Shaffie, "An overview of solar thermal power generation systems," Journal of Solar Energy Research, vol. 3, no. 4, pp. 301-312, 2018.

[8] S. Kalogirou, Solar Energy Engineering, Academic Press, Cambridge, MA, USA, 2014.

[9] B. Reuben, Y. Sam, and C. Juan, "Heat transfer fluids for parabolic trough solar collectors-a comparative study," in Proceedings of the 2017 IEEE Conference on Technologies for Sustainability (SusTech), Phoenix, AZ, USA, October 2017.

[10] A. Reza, M. Heydar, Z. Malihe, D. Mehdi, and G. Sahar, "Heat transfer of nano fluid in a double pipe heat exchanger," International Scholarly Research Notices, vol. 2014, Article ID 736424, 7 pages, 2014.

[11] L. Chen, C. Xu, J. Liu, X. Fang, and Z. Zhang, "Optical absorption property and photo-thermal conversion performance of graphene oxide/water nanofluids with excellent dispersion stability," Solar Energy, vol. 148, pp. 17-24, 2017.

[12] W. Herchie, "Solar energy strategies in USA utility market," Renewable Energy and Sustainability Energy Reviews, vol. 177, pp. 590-595, 2017.

[13] J. Chao, L. Peiwen, W. Kai, and E. Edgar, "Survey of properties of key single and mixture halide salts for potential applications as high temperature heat transfer fluids for concentrated solar thermal power systems," Journal of AIMS Energy, vol. 2, no. 2, pp. 133-157, 2014.

[14] L. Frantz and K. Kai, "Engineered nanomaterial in electronics and electrical industries," Hand Book of Silicon Based MEMS Materials and Technologies, Elsevier, Amsterdam, Netherlands, 2nd edition, 2015.

[15] P. Sivashanmugam, "application of nanofluids in heat transfer phenomena," in An Overview of Heat Transfer Phenomena, N. K. Salim, Ed., Intech Open, London, UK, 2012, http://www.intechopen.com/books/an-overview-ofheat-transfer-phenomenon/application-of-nanofluids-inheat-transfer.

[16] L. Dan, X. Wenjie, and F. Wenjun, "Preparation and properties of copper-oil-based nanofluids," Nanoscale Research Letters, vol. 6, no. 1, p. 3733, 2011. 
[17] M. Kawira, R. Kinyua, and J. Kamau, "A prototype parabolic trough solar concentrator for steam production," Journal of Agriculture Science and Technology (JAGST), vol. 14, no. 2, 2012.

[18] M. Kawira, R. Kinyua, and J. Kamau, "Investigating a porotype heat exchanger for steam storage," Journal of International Organization of Scientific Research, vol. 6, no. 4, pp. 70-80, 2014.

[19] P. Mlatho, "Experimental performance of solar receivers designed to use oil as heat transfer fluid," ISRN Renewable Energy, vol. 2011, Article ID 851764, 13 pages, 2011.

[20] S. Anbu, S. Venkatachalapathy, and S. Suresh, "Heat transfer and pressure drop studies of $\mathrm{TiO}_{2} / \mathrm{DI}$ water nanofluids in helically corrugated tubes using spiraled rod inserts," Heat and Mass Transfer, vol. 54, no. 5, pp. 1301-1311, 2018.

[21] R. G. Srinivasa, N. Haribabu, and C. J. Rao, "Heat transfer analysis on shell and tube heat exchangers," International Journal of Research in Aeronautical and Mechanical Engineering, vol. 2, no. 1, pp. 11-26, 2014.

[22] G. F. Vera, C. R. Garcia, J. Gonzalez et al., "A simplified model for shell and tube heat exchangers: practical application," Applied Thermal Engineering, vol. 30, pp. 1231-1241, 2010.

[23] G. F. Hewitt, Heat Exchanger Design Hand Book, Begell House Publishing Ltd, Leeds, UK, 2002.

[24] H. Berhane, M. Medrano, M. Filipe, and B. Dieter, "Optinum heat exchanger area estimation using coefficients of structural bonds: applications to an absorption chiller," International Journal of Refrigeration, vol. 33, no. 3, pp. 529-537, 2010.

[25] R. Shah and D. Sekuli, Fundamentals of Heat Exchanger Design, John Wiley \& Sons, Hoboken NJ, USA, 2003.

[26] TEMA, Pressure Vessel Code-Alternate Rules', TEMA, New York, NY, USA, 1993.

[27] M. Ambarish and C. Gautam, Improvement of Heat Transfer through Fins: A Review of Recent Developments, Wiley Online Library, Hoboken, NJ, USA, 2020.

[28] U. Muhammad, S. Usman, and M. Hafiz, "Recent advances in application of nanofluids in heat transfer devices: a critical review," Journal of Renewable and Sustainable Energy Reviews, vol. 103, pp. 556-592, 2019. 